\title{
1
}

\section{What are the 'Classic' Articles in Cartography?}

\section{Martin Dodge}

School of Environment and Development, University of Manchester, UK

\subsection{Outline of the Book}

The intention of Classics in Cartography is to provide an intellectually-driven reinterpretation of a selection of some of the most influential articles from the last thirty years of academic cartography research. The ten chosen 'classic' articles were written by a range of the leading academic cartographers, geographers and allied scholars. They were all published in the international peer-reviewed journal Cartographica.

While the ten 'classic' articles are diverse in their agendas and approaches, they are all thought provoking texts that demonstrate how different aspects of mapping work as a mode spatial representation; they also shed light how different cartographic practices have been conceptualised by academic researchers. They are reprinted in full in this volume and, importantly, they are accompanied by newly commissioned reflective essays by the original authors (or other eminent researchers) to provide fresh interpretation on the meaning of the ideas presented and their wider, lasting impact on cartographic scholarship. Moreover, these essays give insights into how academic ideas emerge and some present a personal perspective on the nature of scholarly research. As such it is hoped that they will furnish current and future researchers with insights into how influential academic ideas come about and circulate as catalysts that can codify and instigate important areas of research within cartography and generate novel theoretical perspectives on mapping. While the focus on past 'classics' is perhaps rather backward looking in an era of such rapid social and technical change in cartography, it can be counter-argued that today there is real intellectual value in historical reflection because of the ways it helps us to understand better the present context for cartographic studies and to better inform future strategies for more innovative, creative mapping research (Dodge, Perkins and Kitchin, 2009; Kitchin and Dodge, 2007).

Classics in Cartography: Reflections on Influential Articles from Cartographica Edited by Martin Dodge (c) 2011 John Wiley \& Sons, Ltd 
The book's intellectual focus on reflecting on 'classic' work in cartographic research, as opposed to GIScience or geovisualization is a conscious decision (see Dodge, McDerby and Turner, 2008; Fisher, 2006 for coverage of these allied fields). There is a strong case that cartography, broadly conceived, has become a newly reinvigorated topic in recent years, and that mapping has growing relevance to many scholars and students across the social sciences and humanities disciplines (Dodge and Perkins, 2008). The turn towards the 'visual' and 'spatial' in many large social science disciplines (such as anthropology, literary studies, sociology, history and communications) means there is extensive interest in spatial representations and mapping practice in its many forms (Warf and Arias, 2008). Meanwhile, mapping approaches are also proving instrumentally powerful in the information sciences, bio-informatics and human-computer studies as the basis for novel knowledge discovery strategies (Börner et al., 2009). There is also much more lively engagement with cartography beyond academia, with growing artistic interest, numerous exciting participatory mapping projects and, of course, mass consumer enrolment of interactive spatial media on the Web, on mobile phones and in-car satellite navigation systems to solve myriad daily tasks (Crampton, 2009; Elwood, 2010).

So, looking beyond the core readership in cartography and GIScience, it is hoped that Classics in Cartography will have utility more widely across the sciences, social sciences and humanities, meeting the needs of a range researchers and postgraduate students interested in maps. It provides a new route into the wealth of significant cartographic literature, a unified and coherent way to bring a range of important mapping theories to the attention of a wide range of people looking to intellectually inform their mapping practice. The combination of 'classic' articles with new interpretation, which includes the significant work of many of the most well known cartographic scholars, makes this a uniquely useful book.

\subsection{Delimiting the Cartographic 'Classics'}

At the heart of the academic discipline of cartography are a set of theoretical frameworks and empirical findings that provide the intellectual basis for understanding the nature of maps and the work they do in the world. While such theories and findings are often the incremental product of the collective thought of many scholars, there are also signature pieces of writing that become recognized as 'classics' because of the way in which they push forward understanding or praxis by a significant degree. Such books and articles, through dint of their novel insights, analytic rigour or breadth of scholarship, gain recognition as foundational touchstones for students and academic researchers in cartography.

However, the task of drawing up a short and definitive list of such 'classic' work for any academic discipline that would achieve widespread agreement is an almost impossible one. The idiosyncratic interests, personal biases, partial knowledge and political agendas of the list maker will always mean the selection is less than perfect. To begin there are multiple dimensions upon which 'classic' status can be defined and the judgements made are almost always subjective. Perhaps most obviously a 'classic' might 
be delineated in terms of the degree of novelty and originality in the material: being first to publish can often be crucial in claiming rights to found a field of research. Additionally, 'classic' status might be judged by the impact the paper or book has in terms of setting on-going research agendas and acting as the initiator of something bigger - it is a 'classic' not so much for what it is but because of what it caused. Along a different track, it could be argued that some writing is rightly regarded as 'classic' because it is an archetypal model or stylish synthesis of a large and important body of knowledge, it elegantly encapsulates an argument better than rest, and the quality of expression and depth of scholarly interpretation means it becomes widely referenced as the definitive source. Such articles and books can also be powerful in pedagogic terms giving students and the next generation of academics their 'route maps' into ideas and interpretation of the literature. So 'classics' are classic because teachers and textbooks cite them as such. The longevity of the work can also award 'classic' stature as ageless pieces that every serious student and new scholar must read (although many do not!). A piece of work can also be elevated to the prominence of a 'classic' because it provides a convenient shorthand signifier for a much large body of scholarship by one academic or research group; it becomes the totemic masterwork of a lifetime of research. This is particularly the case where scholarly reputations inflate and evolve after the death of the person concerned. One could argue, for example, that J.B. Harley's 'classic' article Deconstructing the Map (Chapter 16), which was published shortly before his sudden death in 1991, has subsequently been cited oftentimes as a summary of his larger body of work on the politics of maps.

'Classics' can also emerge because what they say becomes the centre of controversy, either by accident or deliberate design by the author. Such pieces can spark a flurry of responses and commentaries in journals - and now online discussions and blog posts and also generate an inflated citation score. While sometimes pieces can become a 'classics' because they got things wrong and are seen as prime exemplars of how misguided scholars were in the past. Others become elevated as talismans of failed paradigms or as placeholders for politically unacceptable viewpoints of previous generations (e.g. in political geography dealing with the overt colonial ideologies of past in Halford Mackinder's writing with its infamous 'Heartlands' mapping, Blouet, 2005; or the racist agenda underlying the cartographic analysis of W.Z. Ripley, Winlow, 2006).

This kind of revisionism also begs the questions, is 'classic' a permanent state - once its achieved, does it remain forever more? Perhaps it is less so now given the extent to which theories seem to change with fashion and the rapidity of cycling through research agendas in contemporary social science scholarship. Consequently, 'classic' status must be regarded as provisional: a touchstone piece for the in vogue paradigm can become moribund as the core research agenda shifts and it is superseded by other, better - or perhaps just different - work. And, one of the interesting academic games is to try to find such 'lost classics' and resurrect them to bolster a newly emerging perspective.

Beyond these intellectual issues, subjective judgements and temporal fluctuations, there is a panoply of projects that seek to 'scientifically' assess the most significant scholarly work using citations counts, impact factors, h-scores and an assortment of other quantitatively derived metrics. Such calculative 'classics' seem to offer objectivity, but this is very much a veneer that masks a whole host of messy realities, fallacies and 
contingencies with quantitative approaches, particularly relating to relative comparability through time and across subject areas. As anyone who has used citations knows, the major databases recording them are also incomplete, with varying coverage over time, by language, publishing formats and academic disciplines. The partiality of the data sources is easily highlighted in their inconsistencies when comparing citation scores for the same article across the three main databases (e.g. citations to my 2007 paper Rethinking Maps: ThompsonISI's Web of Science: 13; Google Scholar: 32; Elsevier's Scopus: 17). Moreover, the practices and intellectual significance of citations varies across scholarly domains, which means measuring 'classics' absolutely, in quantitative terms, across subjects areas is unworkable.

Yet these acknowledged flaws in citations do not stop a significant degree of fascination with such metrics by academics (particularly, perhaps, by those who seem to have high scores or want higher ones!), by promotion committees, grant giving bodies and government funding agencies. Increasingly over last decade, quantitative assessment of the significance of published work has figured in efforts to systematically profile academics, allocate funding amongst departments and rank institutions in the name of improving quality, rewarding so-called research excellence and achieving greater value for money. It is interesting to ponder how cartographic research - with a relatively small core body of active scholars and particular publishing practices and arguably peripheral outlets - fares in these kinds of citational games.

High citation scores are no guarantee of scholarly quality or intellectual significance; they are at best a popularity indicator. Controversial articles get cited just for being controversial, not necessarily because they are good. Poor quality work can pile up citations simply because its visible or easily accessible. Other articles can accrue citations because of assiduous self-promotion by authors and through lazy citation practices by fellow academics (too many of us cite articles or book as 'tokens' of credibility without ever having read them).

An interesting alternative to the admittedly subjective individual list-maker and attempts at objective metrics would be to try a robust qualitative approach using a sample survey method. Here a kind of opinion poll would be taken of a wide sample of scholars in a subject area who would be asked to select their 'classics'. Combining multiple selections could generate a consensual view of 'classics', assuming a broadly representative sample of people willing to participate in the poll could be achieved. While this was not done for this book - which is primarily the result of subjective listmaking - it would be a potentially worthwhile exercise to try to draw a more definitive list of cartography's 'classics' by such a polling approach.

\subsection{Why Re-publish ‘Classics'?}

Notwithstanding the problematic task of identifying 'classics', there is certainly an intellectual tradition of evaluating developments in scholarship in terms of such touchstone articles and books, through their re-reading and re-interpretation. Such reflection and appraisal is conducted in a range of forms of academic publishing in many disciplines. For example, leading disciplinary journals, such as Progress in Human 
Geography, regularly consider citation 'classics' with the goal of 'reflecting on books and other works that have more than stood the test of space and time in shaping the discipline and practice of human geography'. Over the years a number of books reprising 'classics' from a specific sources - journals, institutions and research groups - are put together: Peter Fisher, for example, edited a large collection of Classics from IJGIS (2006), which reprinted nineteen important articles, accompanied by reflective essays, from the International Journal of Geographical Information Science. There is also a practice of publishing festschrifts of the 'classics' work of eminent scholars as a reflection and celebration of their contribution to the intellectual progress of disciplines. Examples include The New Nature of Maps, a posthumously edited collection of Brian Harley's later theoretical papers on cartography put together by Paul Laxton (2001), and Land and Life, edited by John Leighly (1976), presented significant work of Carl Sauer.

In pedagogic terms a range of different kinds of collections of 'classics' are a staple of academic publishers. Produced chiefly as primers for undergraduate students, examples include: Human Geography: An Essential Anthology (1996) edited by John Agnew and colleagues. A large number of reader style volumes that try to provide synoptic coverage of a body of literature by excerpting from 'classic' work often with editorial interpretation have been produced over the last decade as well (e.g. Moseley et al.'s Introductory Reader in Human Geography, 2007). Other books focus solely on the interpretation of 'classics', without actually reprinting or excerpting the originals: Hubbard, Kitchin and Valentine (2008), for example, edited Key Texts in Human Geography, a successful collection of essays appraising twenty-six of the most significant books for the discipline. More broadly there are now host of disciplinary dictionaries, introductory handbooks and larger encyclopaedia projects that seek to codify an academic field, in part, by identifying and evaluating 'classic' material.

Such anthologies, readers and key texts type books, while often aimed at students, are also important because the selection decisions of the academic editors ineluctably also provide signifiers in terms of 'what matters' intellectually. They influence directly what student's see, read and come to regard as the canons of the discipline. More broadly, it might be argued that there is scholarly value in this raft of reflective publishing, in that it can help cut through 'information overload' generated by bibliographic databases and ready online access to e-journals and digital books. A coherently edited collection can save much time and effort for students and academics in tracking down a set of the landmark articles that are otherwise scattered across many decades worth of journal issues (much of which can now be quickly downloaded but without means or indicators to determine what is worth reading). In summary, the wide range of competing and complimentary reflective efforts does, in some senses, establish the merit of considering 'classics' in cartography.

\subsection{Choosing the 'Classics' in Cartography from Cartographica}

The task of drawing up top ten lists of academic articles is at one level a rather worthless exercise, yet it can focus minds and provide a starting point for considering what are the 
most significant works and why. Also, given peoples liking for such 'list-o-mania', it can also offers up some prurient entertainment, talking points at seminars and something to argue over at conference lunch lines!

In the initial planning of this book it was decided to use the 'top ten' approach ${ }^{1}$ as an organizing principle and also to focus on a single core disciplinary journal as the source. ${ }^{2}$ In drawing up a shortlist of 'classics' from the wide array of high-quality material published in the four decades worth of Cartographica, an effort was made to select articles that have provided significant contributions to advance cartographic thought and praxis. This was guided, in part, by looking at citations counts of articles but this was not in itself seen as a sufficient or always reliable indicator of significance. Therefore, a sizeable degree of subjective editorial judgement was also involved in the final selection of 'classics'.

The decision to focus solely on the journal Cartographica as the source rather than to look more widely across other peer review outlets was a conscious choice and offers several advantages. From the mid-1960s Cartographica has grown into a key academic guiding force in cartography, reflected in both the breath and quality of the research articles it has published over the years. It now enjoys a well established international reputation for publishing innovative peer-reviewed work, with material submitted from a broad range of scholars in cartography, GIScience, human geography and allied disciplines. It has been the outlet of choice for many landmark pieces of research along with some larger monographs, particularly during the 1980s. It has published several hundred peer-reviewed research articles covering a huge breadth of ideas and approaches to mapping. It now has extensive historical archives, having been produced continuously since 1964, and is currently published on a quarterly basis by University of Toronto Press. (Further discussion of the historical context of Cartographica is provided in Jeremy Crampton's foreword.)

Using peer-reviewed articles only from Cartographica was felt to be a strength in the book's intellectual design, not a weakness. It has positive virtues of concentrating the choice on a cogent and high-quality range of material. It would be fair to say none of the other cartography journals has the same international reputation for publishing innovative research and for intellectual leadership. While the use of Cartographica alone is an arbitrary decision, widening sourcing to look across multiple cartography journals would have increased the diversity of selected material but would not have necessarily identified a higher quality set of 'classics' or improved the insight offered by this volume.

Looking for 'classics' across more journals would have made selection decisions that much harder and also raised thorny boundary issues - what is cartography and what is not. (In some senses this was side-stepped here - if it was published in Cartographica, it

\footnotetext{
${ }^{1}$ Of course ten is an arbitrary but universal feature of the mania for lists. Psychologically, ten seems like a good number-large enough to be useful but not too long to be unwieldy and impossible to grasp. It does not mean there are only ten 'classic' articles in Cartographica - it could easily have been fifteen or twenty. However, ten also fits pragmatic demands of publishers for a scale of book that is commercially viable. ${ }^{2}$ I am very grateful to the assistance of Jeremy Crampton in formulating the book and in the process of selecting 'classic' material for inclusion. Note, Jeremy currently serves as editor of Cartographica. I serve on the editorial board of the journal.
} 
counts as cartography!). Defining the scope of any academic field is a problematic task because where to draw the intellectual boundaries cannot be objectively decided. What lies inside the disciplines borders is subjective, related to individual's interests and experience. (Indeed, is everything published in Cartographica actually about cartography? This depends on your viewpoint.). How do you police the scholarly margins and handle overlaps with other subjects, particularly given the broad nature of mapping. Cartographic research has many shared interests with a raft of quantitative methods, regional geography, surveying, along with graphic design, aesthetics, statistical analysis, photogrammetry, to name but a few fields. The rise of research focused on GIS techniques and concepts since the late 1980s, and latterly GIScience has come to eclipse cartography and absorb much of mapping research. This changing domain focus is reflected in the changed names of cartography journals to include GIS in their titles and to encompass the topic as a key remit for relevance (for example, The American Cartographer changed to CaGIS, Cartography and Geographic Information Systems, in 1990).

In the initial intellectual design of the book it was not apparent that there were any attempts to produce a list of the most highly cited work across cartographic literature in general. However, under the editorship of Jeremy Crampton, a useful 'top ten' list of the articles published in Cartographica based on a citation metric was drawn up not long ago (Table 1.1). This was done, in large part, as a promotional device for the journal, with the ten articles being 'given away' as free downloadable pdfs on the University of Toronto Press website. ${ }^{3}$ The 'accuracy' of the citation data is open to question (particularly given the partial coverage of the source) but the selection does identify an interesting range of work, including pieces by scholars that would be widely acknowledged in cartography. The interpretative text accompanying this list notes how a couple of pieces 'focus on the representation of elevation data, presciently foreshadowing today's interest in virtual globes and terrain representation' and, more generally, the selection highlights the 'deep ties between cartography and GIS' (www. utpjournals.com/carto/CARTO_post.pdf).

While this list, derived solely from citation counts, was a helpful initial point of reference for identifying the 'classics' for this book, it did not by itself seem sufficiently robust to use in totality. While there is a $40 \%$ overlap between this list and the ten 'classics' eventually chosen for this collection, it was felt that 'raw' citation counts resulted in a rather unbalanced selection, that in particular tended to favour technical and algorithmic pieces above more philosophical, political and design-orientated work. Some papers seemed to speak much more to a GIS audience rather than scholarship around cartographic representations and mapping practice. The goal for this book was different from the needs of commercial promotion for the journal, seeking a broader view of cartographic research and a greater diversity of authorship to capture wider range of approaches and intellectual perspectives. For example, the 2007 citation-based 'top ten' list featured two papers by both J.B. Harley and David Mark - this kind of

\footnotetext{
${ }^{3}$ Online at http://utpjournals.metapress.com/content/120327/. It would be interesting to see if this promotional exercise increased the reading and citing of these selected pieces and, as such, re-enforced their 'classic' status.
} 
Table 1.1 A top ten listing of the most highly cited articles published in the journal Cartographica. It was drawn by Jeremy Crampton based on Elsevier's Scopus citation database in December 2007. Articles ranked according to number of citations

\begin{tabular}{|c|c|c|c|c|}
\hline & Author(s) & Date & Title & Volume \\
\hline 1 & Harley, J.B. & 1989 & Deconstructing the Map & $26(2)$ \\
\hline 2 & Mark, D.M. & 1984 & $\begin{array}{l}\text { Automated Detection of Drainage Networks } \\
\text { From Digital Elevation Models }\end{array}$ & $21(2 / 3)$ \\
\hline 3 & $\begin{array}{l}\text { Langran, G. } \\
\text { and Chrisman, N.R. }\end{array}$ & 1988 & $\begin{array}{l}\text { A Framework for Temporal Geographic } \\
\text { Information }\end{array}$ & $25(3)$ \\
\hline 4 & Peuquet, D.J. & 1984 & $\begin{array}{l}\text { A Conceptual Framework and Comparison of } \\
\text { Spatial Data Models }\end{array}$ & $21(4)$ \\
\hline 5 & $\begin{array}{l}\text { Mark, D.M. } \\
\text { and Csillag, F. }\end{array}$ & 1989 & The Nature of Boundaries on 'Area Class' Maps & $26(1)$ \\
\hline 6 & Monmonier, $\mathrm{M}$. & 1990 & $\begin{array}{l}\text { Strategies for the Visualisation of Geographic } \\
\text { Time-Series Data }\end{array}$ & $27(1)$ \\
\hline 7 & Blakemore, $\mathrm{M}$. & 1984 & Generalisation and Error in Spatial Data Bases & $21(2 / 3)$ \\
\hline 8 & Harley, J.B. & 1990 & Cartography, Ethics and Social Theory & $27(2)$ \\
\hline 9 & Carter, J.R. & 1992 & $\begin{array}{l}\text { The Effect of Spatial Precision on the } \\
\text { Calculation of Slope and Aspect Using Gridded } \\
\text { DEMs }\end{array}$ & $29(1)$ \\
\hline 10 & Kumler, M.P. & 1994 & $\begin{array}{l}\text { An Intensive Comparison of Triangulated } \\
\text { Irregular Networks and Digital Elevation } \\
\text { Models }\end{array}$ & $31(2)$ \\
\hline
\end{tabular}

duplication was avoided. The citation-based list also seemed to be missing a number of noteworthy scholars who have written interesting and insightful pieces for Cartographica, such as Denis Wood and Matthew Edney.

Furthermore, the time span of the citation-based 'top ten' list was overly narrow, with all the papers identified having been published in a ten year window from 1984 to 1994 (with three published in a single year, 1984). Given that Cartographica started publishing in 1965 (known then as The Cartographer) and continues to the present day, it was felt a more even distribution of 'classics' through time would be appropriate and hopefully capture more of the changing nature of cartographic scholarship during the past forty plus years. In particular, the fact that the 'top ten' citational list included no 'classic' from the last fifteen years seemed odd (one might argue this is statistically correct but not intellectually justifiable). The underlying citational statistics themselves (generated with Elsevier's Scopus database) also have a question mark against them, as they apparently missed out Douglas and Peucker's 1973 article, which has highest citation count by significant margin, approximately double J.B. Harley's, according to Google Scholar (Table 1.2).

The rationale then for the 'classic' articles actually selected for inclusion Classics in Cartography was somewhat of a subjective fudge! (Table 1.2) It was felt necessary to look beyond citations to choose other less visible articles that are intellectually significant overlooked 'classics' perhaps. The book needed wider coverage through time and with a broader range of recognizable authors. The selection tried to incorporate articles which 
Table 1.2 The ten 'classic' peer-reviewed articles from the journal Cartographica selected for this volume. Articles ranked according to their date of publication

\begin{tabular}{|c|c|c|c|c|c|}
\hline & Author(s) & Date & Title & Volume & Citations $^{a}$ \\
\hline 1 & $\begin{array}{l}\text { Douglas, D.H. } \\
\text { and Peucker, T.K. }\end{array}$ & 1973 & $\begin{array}{l}\text { Algorithms for the Reduction of } \\
\text { the Number of Points Required to } \\
\text { Represent a Digitised Line or its } \\
\text { Caricature }\end{array}$ & $10(2)$ & 1088 \\
\hline 2 & Guelke, L. & 1976 & $\begin{array}{l}\text { Cartographic Communication } \\
\text { and Geographic Understanding }\end{array}$ & $13(2)$ & 18 \\
\hline 3 & Peuquet, D.J. & 1984 & $\begin{array}{l}\text { A Conceptual Framework and } \\
\text { Comparison of Spatial Data } \\
\text { Models }\end{array}$ & $21(4)$ & 256 \\
\hline 4 & $\begin{array}{l}\text { Wood, D. } \\
\text { and Fels, J. }\end{array}$ & 1986 & $\begin{array}{l}\text { Designs on Signs: Myth and } \\
\text { Meaning in Maps }\end{array}$ & $23(3)$ & 73 \\
\hline 5 & $\begin{array}{l}\text { Mark, D.M. } \\
\text { and Csillag, F. }\end{array}$ & 1989 & $\begin{array}{l}\text { The Nature of Boundaries on } \\
\text { 'Area Class' Maps }\end{array}$ & $26(1)$ & 106 \\
\hline 6 & Harley, J.B. & 1989 & Deconstructing the Map & $26(2)$ & 555 \\
\hline 7 & Monmonier, M. & 1990 & $\begin{array}{l}\text { Strategies for the Visualisation of } \\
\text { Geographic Time-Series Data }\end{array}$ & $27(1)$ & 91 \\
\hline 8 & Edney, M.H. & 1993 & Cartography Without 'Progress' & $30(2 / 3)$ & 43 \\
\hline 9 & Sparke, M. & 1995 & $\begin{array}{l}\text { Between Demythologising and } \\
\text { Deconstructing the Map }\end{array}$ & $32(1)$ & 28 \\
\hline 10 & $\begin{array}{l}\text { Elwood, S. } \\
\text { and Ghose, R. }\end{array}$ & 2001 & $\begin{array}{l}\text { PPGIS in Community } \\
\text { Development Planning }\end{array}$ & $38(3 / 4)$ & 26 \\
\hline
\end{tabular}

${ }^{a}$ Citations according to Google Scholar, March 2010.

changed the purview and remit of sub-disciplinary fields of cartography. The result is a selection of articles that represents a wide range of cartographic interests, and includes work by many of the most influential scholars of the last few decades. It is undoubtedly an idiosyncratic list, and is perhaps too eclectic, but hopefully it is also a plausible list of the 'classics' in scholarly cartographic research that have appeared in the journal Cartographica.

The selected 'classics' have a widely variable range of citation counts, from over one thousand to a couple of articles with under fifty. For example, there is the foundational work of Douglas and Peucker on cartographic generalization that has been cited 1088 times according to Google Scholar (March 2010) and is referenced in myriad of places across the Web. The second most-cited article in this collection is quite different, but no less influential, being a very well known piece by Brian Harley, often credited with changing the way we think about maps in social terms. Harley's article from 1989 has over five hundred citations and remains influential across the social sciences.

While they cover a fairly wide time span - nearly thirty years - there are unfortunately none identified and selected from the very earliest volumes of Cartographica. Equally, the latest issues are not as well represented as needed, with the most recent article selected as a 'classic' being Elwood and Ghose's 2001 research on PPGIS. Looking at the dates of the pieces listed in Table 1.2, it is still somewhat evident of a bulge of material 
selected as 'classics' from the later half of the 1980s. Perhaps this does represent a purple patch for cartographic scholarship that became eclipsed by the growth in GIS research in subsequent years.

In terms of structuring the selected 'classics' in this volume, we did not want to present them in chronological order (or the reverse, from new to old) as this can imply simple linear progress and a naive narrative of improvement over time. The reality is research from different time periods is different and cannot be easily evaluated as better or worse based on when it was published. Also, we did not want to present the ten 'classics' ranked by their citation count. Again this implies a spurious hierarchy in scholarly worth and reifies the citation, which, as discussed above, is a problematic measure of quality. Instead, it was decided that Classics in Cartography would be organized thematically, allowing readers to see links between key ideas and debates in academic cartography. The ten articles were grouped into three broad sections: epistemological practice; ontological understanding; and politics and society.

In terms of the editorial process all ten 'classic' articles from Cartographica are reprinted in full here. They have all been reformatted for consistency and to remove variability of layout and referencing style evident in the original versions published in the journal. The degree of standardization, particularly the switch from footnote citations to Harvard style referencing in a couple of articles, has necessitated some very minor changes to the texts themselves. Nearly all the original illustrations have been faithfully redrawn for this book by Graham Bowden (Cartographic Unit, University of Manchester) to ensure higher quality reproduction than the pdf scans available from the University of Toronto Press.

\subsection{The Significance of Scholarly Reflection}

What is the value in reflecting on 'classic' articles? It is perhaps one of the distinctive practices of scholarship that much effort is expended in understanding how we work, where ideas come from and what influences the development of a discipline. This can be regarded as mere academic navel gazing or dismissed as vainglorious posturing. (And, of course, there are elements of self-indulgency, vanity and ego involved.) However, I would strongly argue that the reflective approach taken by Classics in Cartography has significance because it exposes how knowledge construction proceeds. It 'lifts the lid' on the messy practices of research and the uncertainties in the writing process. It highlights how provisional ideas and theories often are. This back story is typically left out of the finished product - the edited, proofed and professionally formatted article in the journal appears concrete and complete. The published article is like the ship in the bottle, upright and ready; what a reflective approach offers is the chance to narrate the unwritten story of how the ship actually got into the bottle. In some regards this is often as interesting (and perhaps sometimes more interesting) as the finished product. Such reflection can provide new insights when read against the original articles, especially for younger scholars or for outsiders who are coming to the material for first time.

Now is also a good time to contemplate and reflect upon the nature of cartographic scholarship. It seems contemporary academia is trapped by ever increasing pressures to 
publish, the speeded-up cycles of submission and review, the 'salami slicing' of research to generate multiple 'new' papers that are thin on original material, the growth in the size of journals and a proliferation of outlets, the pressure to measure the impact of articles, the need to be setting the next agenda and to demonstrate an international profile. It might be argued that these processes, working in concert, are diminishing the intellectual value of peer-reviewed articles today. The rapidity of circulation of research findings and the relentless attempts to promote new approaches mean it is increasingly hard to keep up and identify what is important. (Often it seems we run and run in our academic 'hamster wheels' without moving forward). The rate and volume of published research needed to be a 'successful' scholar today does not necessary promote quality or allow the time for genuine innovation. As such, it could be argued, that the time is now ripe for more measured reflection and consideration of the past ideas in cartography, rather than running blindly into the future.

For this volume, thoughtful reflection was sought on how scholarly ideas in cartography originate, circulate and come to be influential. Authors of the new essays were requested to be personal, anecdotal and opinionated if they wanted to. And in many cases they have grasped this opportunity and are genuinely introspective about the uncertain processes of authorship. They were also tasked to make their reflection essays accessible to readers without deep theoretical background in the particular field. The added value of the reflective essays are also significant in how they highlight the position and biography of the authors, which is useful for seeing how now-established scholars were working earlier in their careers. Many of the essays discuss the wider significance of the original Cartographica articles in relationship to cartography debates and issues current at the time of writing, and consider how the value of the article has changed - and continues to influence - the way scholars understand the map. Some also consider whether the original article is right to be regarded as a 'classic'. Box 1.1 is a listing of the types of themes that the authors were asked to consider in their reflective essays. This was not a rigid template and the style and substance of essays is quite variable, which is inevitable and also refreshingly realistic.

In terms of the preparation of the new reflection essays, six out ten were written by the original authors (or joint authors) of the Cartographica articles. In the case of David Mark and Ferenc Csillag's 1989 'classic' article, The Nature of Boundaries on 'Area Class' Maps, the reflection essay was of necessity put together solely by David Mark, as Ferenc Csillag passed away in 2005. The remaining three reflection essays were not written by the original authors, but by other eminently qualified scholars; they obviously have a different tone and perspective. J.B. Harley died in 1991 and the task of re-interpreting his 'classic' article, Deconstructing the Map, was taken up enthusiastically by Jeremy Crampton. Donna Peuquet was asked to reflect upon her 1994 article, A Conceptual Framework and Comparison of Spatial Data Model, but was unfortunately unable to participate due to pressure of other writing commitments; Jeremy Mennis gamely stepped up to the task of writing the essay. Lastly, the reflection essay for Len Guelke's 'overlooked classic' from 1976, Cartographic Communication and Geographic Understanding, was undertaken insightfully by Muki Haklay and Kate Jones; Len, himself, did not feel up to the task as he is happily ensconced in other more interesting retirement projects. 


\section{Box 1.1 Themes for Author Consideration}

- Genesis of the theoretical ideas in the paper.

- Context in which the paper was written, reviewed and published. Discuss the wider significance of the paper in relationship to cartography debates and issues current at the time of writing.

- Consider the initial impact and reception of the paper at the time of publication.

- How has the paper influenced ideas over time? Evaluate how it has subsequently been cited, critiqued and incorporated into academic cartography discourse.

- Re-interpret your paper with the power of hindsight and reflect on the lasting validity of the paper's main arguments, methods and sources of evidence. Do you stand by the arguments and ideas presented in the paper? What did the paper do well and what were its weaker points? Does it contain mistakes and things you would now change? How have your ideas changed subsequent to publication?

- Do you agree that it is a 'classic?' Why do you think it's proved to be influential?

- Discuss how the broader field of cartography that your paper relates to has subsequently developed. Has it grown? Or shrunk in importance? Has it taken unexpected directions? Is it now overlooked perhaps?

\subsection{Epilogue}

Over the past couple decades there has been a sustained scholarly engagement in thinking about the ontological basis of cartographic representation and exploring new epistemologies of mapping. Moreover, there is a burgeoning interest from many scientists, social scientists and humanities scholars in theorizing the nature of cartography and productively applying mapping and geographic visualization to solve research problems they face. This coupled with tremendous socio-technical developments in the production of cartographic representations has led to a widening and more vibrant array of different kinds of mapping employed by scholars. The goal in editing Classics in Cartography is to further advance theoretical understanding of cartography in terms of social science scholarship by reflecting on some of the significant ways maps have been researched. Hopefully, the reflection essays, in combination with the original Cartographica articles, work as a useful set of intellectual signposts, particularly for postgraduates and new researchers, in understanding the evolution of 'classic' cartographic theories and for developing new mapping ideas. 


\section{References}

Agnew, J., Livingstone, D.N. and Roger, A. (1996) Human Geography: An Essential Anthology, Blackwell, Oxford.

Blouet, B.W. (2005) Global Geostrategy: Mackinder and the Defence of the West, Routledge, London.

Börner, K., Bettencourt, L.M.A., Gerstein, M. and Uzzo, S.M. (2009) Knowledge Management and Visualization Tools in Support of Discovery. NSF Workshop Report (http://vw.slis.indiana. edu/cdi2008/NSF-Report.pdf).

Crampton, J.W. (2009) Maps 2.0. Progress in Human Geography, 33(1), 91-100.

Dodge, M. and Perkins, C. (2008) Reclaiming the map: British Geography and ambivalent cartographic practice. Environment and Planning A, 40(6), 1271-1276.

Dodge, M., McDerby, M. and Turner, M. (2008) Geographic Visualization: Concepts, Tools and Applications, John Wiley \& Sons Ltd, Chichester.

Dodge, M., Perkins, C. and Kitchin, R. (2009) Mapping modes, methods and moments: a manifesto for map studies, in Rethinking Maps: New Frontiers in Cartographic Theory (eds. M. Dodge, R. Kitchin and C. Perkins), Routledge, London, pp. 220-243.

Elwood, S. (2010) Geographic information science: emerging research on the societal implications of the geospatial web. Progress in Human Geography, 34(3), 349-357.

Fisher, P. (2006) Classics from IJGIS: Twenty Years of the International Journal of Geographical Information Science, CRC Press, Boca Raton, FL.

Hubbard, P., Kitchin, R. and Valentine, G. (2008) Key Texts in Human Geography, Sage, London.

Kitchin, R. and Dodge, M. (2007) Rethinking maps. Progress in Human Geography, 31 (3), 331-344.

Laxton, P. (2001) The New Nature of Maps: Essays in the History of Cartography, The Johns Hopkins University Press, Baltimore, MD.

Leighly, J. (1976) Land and Life: A Selection of the Influential Writings of Carl Ortwin Sauer, University of California Press, Berkeley, CA.

Moseley, W., Lanegran, D.A. and Pandit, K. (2007) The Introductory Reader in Human Geography: Contemporary Debates and Classic Writings, Blackwell, Oxford.

Warf, B. and Arias, S. (2008) The Spatial Turn, Routledge, New York.

Winlow, H. (2006) Mapping moral geographies: W.Z. Ripley's races of Europe and the U.S. Annals of the Association of American Geographers, 96(1), 119-141. 
